\title{
Análise dos Parâmetros de Conforto Ambiental: Estudo de Caso na Unidade de Pronto Atendimento de Samambaia no Distrito Federal
}

\author{
LIMA, Renata Rosa Bernardes ${ }^{1}$ \\ LIMA, Eliomar Araújo de ${ }^{2}$ \\ BRAGA, Darja Koss ${ }^{3}$
}

${ }^{1}$ Faculdade de Arquitetura e Urbanismo. Pós-Graduação em Reabilitação Ambiental Sustentável Arquitetônica e Urbanística. UnB - Universidade de Brasília. Brasília-DF - Brasil. renatarbl87@gmail.com ${ }^{2}$ Faculdade de Tecnologia. Pós-Graduação em Engenharia Elétrica. UnB Universidade de Brasília. Brasília-DF - Brasil. eliomarlima@nmi.unb.br ${ }^{3}$ Faculdade de Arquitetura e Urbanismo. Pós-Graduação em Reabilitação Ambiental Sustentável Arquitetônica e Urbanística. UnB - Universidade de Brasília. Brasília-DF - Brasil. darja.kos@uol.com.br

\begin{abstract}
Resumo
O presente trabalho procura repercutir as possibilidades e as limitações distinguidas no contexto de implantação de uma Unidade de Pronto Atendimento (UPA), em termos de requisitos de conforto ambiental. Para investigar as características higrotérmica, acústica, luminosa e visual do espaço, foi escolhida a UPA de Samambaia no Distrito Federal, como objeto de estudo. A investigação foi realizada a partir da concepção qualitativa, de caráter exploratório, utilizando-se de estudos bibliográficos, análise de normas e resoluções vigentes para a implantação de estabelecimentos assistenciais de saúde, observações visuais e fotográficas e aplicação de entrevistas. Após a análise dos dados obtidos, confrontando-os com os requisitos preconizados na literatura que trata do conforto ambiental, verificou-se que a referida UPA não apresenta condições adequadas e satisfatórias em termos de infraestrutura de acesso e atendimento dos usuários.
\end{abstract}

Palavras-Chave: Arquitetura Hospitalar, UPA, Conforto Ambiental.

\begin{abstract}
This study evaluates the conditions of environmental comfort in the Emergency Care Unit (UPA) located in the Federal District, in the light of a theoretical framework based heavily on the contributions of recent years. To investigate the hygrothermal, sound, light and visual space characteristics, we chose the UPA Samambaia, as the object of study. The investigation was taken from the qualitative design, exploratory, using bibliographic research, standards and resolutions in force for the implementation of health care facilities and visual and photographic observations and interview. After data analysis, comparing them with the requirements recommended by the literature on environmental comfort, it was found that the UPA does not have adequate and satisfactory condition in terms of infrastructure.
\end{abstract}

Key-Words: Hospital Architecture, UPA, Environmental Comfort. 


\section{Introdução}

O desenvolvimento das Unidades de Pronto Atendimento (UPAs) tem o propósito de organizar o sistema de saúde no Brasil, desempenhando importante papel para o atendimento assistencial de saúde à população, especialmente a mais carente. De acordo com a Portaria $\mathrm{n}^{\circ} 1.020$ de 2009 (BRASIL, 2009), as UPAs são estruturadas de forma a cumprir o papel de atendimento secundário de média complexidade, tendo como base uma série de serviços médicos prestados pela rede organizada do Sistema Único de Saúde (SUS).

Este artigo foi desenvolvido a partir das análises de contexto da UPA implantada na Região Administrativa de Samambaia no Distrito Federal, consubstanciada pelo levantamento da literatura especializada que trata da arquitetura hospitalar. Consiste de um estudo investigativo sobre as condições de conforto ambiental da Unidade, permitindo identificar situações e problemas que impactam no nível de planejamento arquitetônico. Para tanto, consultaram-se normas, resoluções e portarias vigentes para a implantação de Estabelecimentos Assistenciais de Saúde (EAS), além de um breve histórico da implantação de serviços assistências à saúde no Brasil e a criação da Portaria GM/MS 2.048 de 2002, que implanta as Unidades de Pronto Atendimento em todo território nacional (BRASIL, 2002).

Além das questões de atendimento, uma unidade hospitalar deve contar com uma organização arquitetônica que atenda todos os parâmetros de conforto acústico, luminoso, higrotérmico e visual para a boa qualidade de serviços prestados, tanto para seus funcionários como para os pacientes (Goés, 2011).

Problemas arquitetônicos como ventilação e luminosidade são um dos grandes agravantes ma implantação de alguns EAS, podendo influenciar até na recuperação de pacientes (Goés, 2004). Nesse ponto, o conforto ambiental aparece como forte aliado aos processos de bem-estar e cura de pacientes.

Com o grande crescimento da população do Distrito Federal e cidades do entorno, a infraestrutura dos EAS não suportam a demanda crescente. Não obstante a existência de hospitais regionais e de referência, como o Hospital de Base, localizado no Plano Piloto, Brasília-DF, a grande demanda de serviços assistenciais de saúde, muitas das vezes de baixa complexidade, gera superlotações no atendimento. A implantação das UPAs pretende complementar a atuação dos hospitais, resolvendo problemas de baixa e média complexidades, evitando que os usuários sejam direcionados diretamente para hospitais de referência.

As Unidades hospitalares, independentemente do porte e das condições infraestruturais, devem observar questões arquitetônicas como ventilação, iluminação e acústica para evitar a ocorrência de patologias respiratórias, infectocontagiosas, psicológicas, podendo expor os médicos, servidores, terceirizados e pacientes a riscos de contaminação e de saúde. Nesse sentido, é de suma importância que as UPAs observem os requisitos de conforto ambiental preconizados na literatura acadêmica e especializada, além do material publicado pelo Ministério da Saúde e pela Agência Nacional de Vigilância Sanitária acerca do assunto.

Diante do exposto, o objetivo geral deste estudo é avaliar as condições de conforto ambiental em uma Unidade de Pronto Atendimento, repercutindo as subdimensões higrotérmicas, acústicas, luminosas e visuais das instalações.

Os esforços necessários para empreender esse objetivo compreendem:

- efetuar diagnóstico e avaliação de uma UPA que permita entender os aspectos chaves da arquitetura hospitalar;

- identificar as principais referências técnicas que regulam e regulamentam o setor;

- promover levantamento de dados na UPA selecionada por meio de observações visuais, fotográficas e questionários;

- conduzir análise de dados, confrontando os achados da pesquisa empírica com a base conceitual; e

- Desenvolver as conclusões sobre o estudo, considerando as questões chaves que nortearam o trabalho, além de recomendar trabalhos futuros.

\section{Unidades de Pronto Atendimento no Contexto do SUS}

O Sistema Único de Saúde (SUS) é o resultado não apenas da evolução do modelo de saúde no país, como também de uma nova (re)formulação das políticas assistenciais em saúde. O SUS foi criado 
pela Constituição Brasileira de 1988 e regulado posteriormente pela Lei $n^{\circ} 8.080$ e Lei $n^{\circ} 8.142$. Suas principais diretrizes apontadas no artigo 198 são:

1. atendimento integral, com prioridade para ações preventivas sem prejuízos às ações assistenciais;

2. participação da comunidade e;

3. descentralização, com direção única em cada esfera do governo.

Diante desse novo modelo de implantação, são propostas estratégias de implantação do SUS nos Estados e municípios do país. O sistema foi organizado de acordo com o nível de complexidade dos serviços prestados aos pacientes, sendo eles de nível:

- Primário: procedimentos simplificados e de baixa complexidade, praticados em ambulatórios. Neste nível estão as Unidades Básicas de Saúde.

- Secundário: procedimentos de maior complexidade, praticados em hospitais, ambulatórios de especialidades e unidades de pronto atendimento.

- Terciário: constituído por hospitais de referência, com procedimentos de média e grande complexidade, servindo de subsídios para os demais níveis.

Nesse contexto, as UPAs são responsáveis pelo nível de complexidade secundário com atendimento a pacientes agudos ou crônicos agonizados com ou sem risco imediato de vida. Sua localização, portanto, deve ser privilegiada em relação à malha viária e circulação de transportes coletivos.

Por meio de políticas do Ministério da Saúde para o crescente melhoramento do Sistema Único de Saúde para sustentar os diferentes níveis de atendimento à saúde, foi lançado o programa HumanizaSUS, instituído em 2003, cuja principal proposta é disponibilizar ferramentas e dispositivos para consolidar redes, vínculos e a corresponsabilização entre usuários, gestores e trabalhadores. Ao direcionar estratégicas e métodos de articulação de ações, saberes e sujeitos, pode-se efetivamente potencializar a garantia de atenção integral, resolutiva e humanizada (BRASIL, 2003a).

O Programa HumanizaSUS envolve não apenas questões relacionadas a assistência por parte dos profissionais, como também engloba os aspectos que dizem respeito às estruturas físicas do edifício, concebidas a partir de projetos de arquitetura (Medeiros, 2004). Diante disso, há a possibilidade de se desenvolver ações de aparelhamento das UPAs com vistas ao conforto ambiental, como forma de avaliar as condições higrotérmicas, acústicas, luminosas e visuais do espaço.

\section{Conforto Ambiental no EAS}

A definição de Conforto Ambiental segundo Schmid (2005 apud Gemelli, 2009, p.26) é entendido como sensação de aconchego, proteção e bem-estar. Essa sensação vai além de simples medições de variáveis que influenciam na edificação. Abrange, no termo ambiental, a harmonia do ambiente construído.

Para Corbella e Yannas (2003) uma pessoa está confortável em um ambiente físico quando se sente em neutralidade com o próprio ambiente. No caso dos EAS, o conforto ambiental é um forte aliado na arquitetura, exercendo funções terapêuticas que contribui para o bem-estar do paciente e servidores com a criação de ambientes que, além de acompanharem os avanços tecnológicos, desenvolvam condições de convívio mais humanas.

O conforto ambiental está vinculado diretamente à dimensão bioclimática em que os principais métodos de investigação são o conforto higrotérmico, acústico, luminoso e qualidade do ar.

O conceito de conforto ambiental vem emergindo com intensidade, impactando todas as áreas da arquitetura, especialmente quando se trata da assistência hospitalar. Nos últimos anos o tema ganhou maior enfoque devido às últimas políticas de atenção à saúde promovida pelo Ministério da Saúde e Secretarias de Saúde dos Estados. A política de Humanização implantada pelo Ministério da Saúde é uma dessas políticas com o foco no paciente, o qual é o principal usuário que precisa receber a melhor atenção e atendimento efetivo. Dessa forma, o estabelecimento, segundo uma das diretrizes dessa política, deve promover uma "ambiência acolhedora e confortável", englobando aspectos que dizem respeito à estrutura física dos edifícios e vinculados ao conforto ambiental (BRASIL, 2003a). 
Os aspectos distinguidos neste trabalho para avaliar o conforto ambiental para os EAS, conforme classificação de Kohlsdorf (2004), são: conforto higrotérmico, conforto acústico, conforto luminoso e conforto visual.

Segundo a Resolução RDC/ANVISA $n^{\circ} 50$ da ANVISA (BRASIL, 2002), as condições ambientais de conforto devem considerar os seguintes aspectos:

Os sistemas de controle ambiental nos EAS abrangem duas dimensões: a endógena, que considera o edifício em sua finalidade de criar condições desejáveis de salubridade através do distanciamento das pessoas das variáveis ambientais externas, e a exógena, que observa os impactos causados pelas construções no meio ambiente externo alterando, de forma positiva ou negativa, suas condições climáticas naturais.

\subsection{Conforto Higrotérmico}

O conforto higrotérmico possui uma variação de acordo com a região onde o estabelecimento se instalará. Seu principal objetivo é a distinção das condicionantes de temperatura, umidade relativa e velocidade do ar e qualidade do ar, propiciando ambientes agradáveis por meio da arquitetura.

Segundo a Resolução RDC n50 da ANVISA (BRASIL, 2002, p.106):

Os diversos ambientes funcionais dos EAS solicitam sistemas de condições de Conforto higrotérmico e de qualidade do ar diferentes em função dos grupos populacionais que os frequentam, das atividades que nelas se desenvolvem e das características de seus equipamentos.

A baixa qualidade do ar dos EAS é um problema frequente, problema esse que pode afetar diretamente a saúde dos servidores e terceirizados e, sobretudo, dos pacientes que tipicamente se encontram com a saúde debilitada e com baixa imunidade.

No Brasil, uma das poucas regulamentações que tratam sobre o assunto é a Resolução RE $n^{\circ} 9$ da ANVISA (BRASIL, 2003b), a qual estabelece padrões referenciais de qualidade do ar para ambientes internos de uso público e coletivo, e a Norma ABNT NBR7256 que abrange o tratamento de ar em unidades Médico- Assistenciais (ABNT, 2005).
A literatura traz algumas definições para o conforto higrotérmico. Por exemplo, Corbella e Yannas (2003) assevera que o conforto higrotérmico está ligado diretamente com os princípios bioclimáticos, cujas principais estratégias são:

- controlar o acúmulo de calor;

- procurar dissipar a energia térmica do ambiente; e

- retirar toda umidade em excesso, promovendo o movimento e troca do ar.

\subsection{Conforto Acústico}

A programação arquitetônica do EAS deve obedecer alguns princípios em se tratando de conforto acústico, devido à implantação desses estabelecimentos localizados em zonas de interstícios urbanos, onde a incidência de ruídos vem se agravando a cada dia em virtude do tráfego de veículos e do número de pessoas que trabalham e frequentam esses ambientes.

OConselho Internacional de Ruído tem recomendado que o nível de ruídos não ultrapasse $45 \mathrm{~dB}(\mathrm{~A})$ durante o dia, $40 \mathrm{~dB}(\mathrm{~A})$ durante a noite e $20 \mathrm{~dB}(\mathrm{~A})$ durante a madrugada. Tem-se observado que o nível de ruído na maioria dos hospitais está entre 50 e $70 \mathrm{~dB}(\mathrm{~A})$ e, em algumas situações ocasionais, acima dessa faixa (Portal Educação, 2013),

Em estabelecimentos de saúde, os pacientes normalmente encontram-se com sensibilidade acústica e sistema de alerta mais apurado. Logo, a compreensão pelo projetista na percepção humana do som é de suma importância na definição da programação arquitetônica do edifício.

Segundo Braga e Amorim (2013),

O som é uma sensação causada no ouvido por variações da pressão do ar, produzidas por uma fonte de som, que pode ser um objeto móvel (autofalantes, cordas vocais) ou o ar em movimento (motores, ventiladores, tubos de instrumentos).

A transmissão do som em um ambiente é necessária, podendo trazer efeitos negativos ou positivos dependendo da sua utilização como, por exemplo, o barulho de uma cascata em um jardim interno, ou uma trepidação de macas em um corredor ou carrinhos do EAS. 
Segundo Goés (2011), as condições de conforto acústico pressupõem:

- localização e orientação do edifício em relação às fontes externas de ruído (tráfego, indústrias, oficinas etc.);

- dimensão e posição das aberturas;

- isolamento das paredes e características acústicas dos materiais; e

- redução das fontes internas de produção de ruídos.

Segundo a Resolução RDC $n^{\circ} 50$ da ANVISA (BRASIL, 2002), as normas para o controle acústico devem ser observadas em todos os EAS e seguirem a norma da ABNT: NBR 10.152 - que trata de níveis de ruídos para o conforto acústico, e a norma ABNT NBR 12.179 - que possui normas para o tratamento acústico em recintos fechados. Tais normas tratam também da importância do controle de níveis de ruídos nesses EAS, bem como enfocam a importância, quando se prestam atendimentos de urgência e emergência, que correspondem à missão das UPAs.

\subsection{Conforto Luminoso}

Ailuminação natural deve estar presente no ambiente do EAS para diminuir o estresse do paciente, da equipe e dos acompanhantes e possibilitar a orientação sensorial. Já a iluminação artificial deve propiciar à equipe de trabalho condições adequadas aos procedimentos a serem realizados (Oliveira e Ribas, 1995). Ela deve ser vista sempre como uma complementação e nunca como uma substituição da falta de iluminação natural.

\subsection{Conforto Visual}

De acordo com Góes (2011), a imagem visual pressupõe um projeto de comunicação visual que contemple desde a logomarca que identifica de imediato a instituição até a padronização de uma sinalização externa/ interna, identificação de veículos, impressos, entre outros equipamentos da instituição.

Um importante elemento de contribuição para o conforto visual dos EAS são as cores, além de funcionarem como um elemento de melhoria para a condição visual devido a seus índices de reflexão, a cor possui influência no comportamento do ocupante do espaço incluindo funções terapêuticas. A sua utilização é um item essencial na composição arquitetônica, tanto interna como externamente, trazendo efeitos positivos ou negativos de acordo com a sua escolha.

A sua implantação deve estar relacionada com o tempo de permanência no ambiente como também com a situação de saúde do usuário. Pimentel (1992) apresenta uma síntese, Quadro1, que relaciona a cor e suas influências sobre o ânimo.

\section{Quadro 1: As cores e suas influências}

\begin{tabular}{|l|}
\hline $\begin{array}{l}\text { Amarelo: estimulação mental, concentração. } \\
\text { Incentiva a conversação; }\end{array}$ \\
\hline $\begin{array}{l}\text { Azul: tem efeito tranquilizante e refrescante. } \\
\text { Evita a insônia; }\end{array}$ \\
\hline $\begin{array}{l}\text { Branco: o excesso de claridade pode levar } \\
\text { a um cansaço mental; }\end{array}$ \\
\hline Laranja: estimulante, dá um ar social ao ambiente; \\
\hline Lilás: sedante, pode causar sensação de frustração; \\
\hline Rosa: aconchegante, traz calor sem excitação; \\
\hline Verde: recompõe, equilibra. Efeito regenerador; \\
\hline $\begin{array}{l}\text { Vermelho: excitante, pode deixar as } \\
\text { pessoas agitadas e irritadiças. }\end{array}$
\end{tabular}

Fonte: Pimentel (1992)

Com o objetivo de analisar todos os pontos abordados sobre conforto ambiental em EAS, conforme os apontamentos da literatura, das normas e resoluções vigentes sobre o assunto, foram promovidas visitas junto à Unidade de Pronto Atendimento (UPA) implantada em Samambaia no Distrito Federal. Por meio da realização de recortes fotográficos do estabelecimento e de entrevistas semi-estruturadas, coletarem-se dados, informações e evidências, permitindo identificar as condições ambientais com o intuito de promover uma análise descritiva à luz das subdimensões do conforto ambiental.

\section{Metodologia}

A concepção de pesquisa empregada é de caráter exploratória e descritiva, operacionalizada na forma de um estudo de caso simples. Os métodos utilizados para coleta de dados basearam-se no levantamento de dados secundários, incluindo livros de autores consagrados na área de arquitetura 
hospitalar, artigos e trabalhos acadêmicos que abordam o assunto, bem como o acesso a fontes primárias, como documentos, manuais, normas e entrevistas com os principais envolvidos na unidade de análise, além de levantamento baseado em recortes fotográficos.

A partir de observações visuais da Unidade de Pronto Atendimento de Samambaia no Distrito Federal, constatou-se preliminarmente a existência de possíveis irregularidades infraestruturais em termos de arquitetura hospitalar.

Posteriormente, com o intuito de distinguir o contexto local da UPA de Samambaia, conduziramse atividades de preparação, validação e aplicação dos instrumentos de coleta de dados baseado em entrevistas semi-estruturadas. Os sujeitos da pesquisa foram definidos de maneira pseudoaleatória, procurando obter as impressões e percepções dos principais envolvidos, quais sejam pacientes, usuários, servidores, terceirizados, gestores e prestadores de serviço.

A etapa seguinte envolveu as atividades de organização, classificação, tratamento e compilação dos dados levantados junto à Unidade investigada. Os resultados alcançados propiciaram aos pesquisadores encontrar elementos importantes para posterior análise, de modo a evidenciar os principais achados e a discussão à luz dos pressupostos teóricos deste trabalho. Nos próximos capítulos serão repercutidos os elementos contextuais e descritivos do objeto de análise.

\section{Estudo de Caso}

\subsection{Unidade de Pronto Atendimento de Samambaia}

A Unidade de Pronto Atendimento (UPA) escolhida para o estudo de caso foi a UPA de Samambaia, localizada na QS 107 CONJUNTO 04 Área Especial 05, Região Administrativa de Samambaia no Distrito Federal. As Figura 1a e Figura 1b apresentam recortes fotográficos da fachada principal da Unidade.

Figura 1a: Recorte fotográfico da Fachada Principal UPA de Samambaia

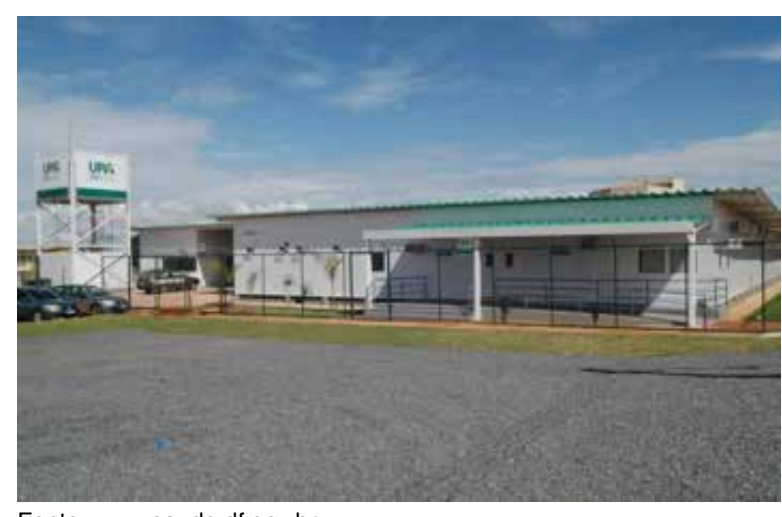

Fonte: www.saude.df.gov.br

Figura 1b: Recorte fotográfico da Fachada Lateral UPA de Samambaia

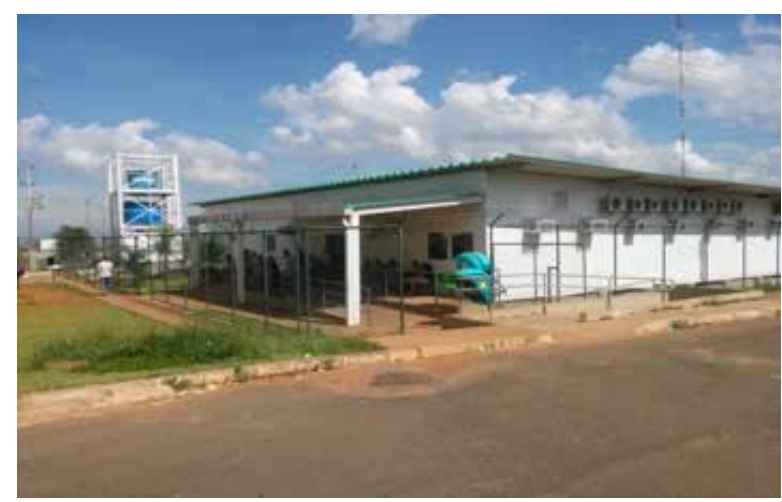

Fonte: O Autor (2013)

A UPA de Samambaia foi inaugurada no dia 15 de fevereiro de 2011 com área construída de 1,3 mil metros quadrados. Está inserida no modelo de porte III, beneficiando uma população de até 300.000 mil habitantes. A classificação das UPAs pelo Ministério da Saúde está disposta na Portaria 1.020 de 2009 (BRASIL, 2009), conforme pode ser observado no Quadro 2.

Quadro 2: Classificação das UPAs - Portaria 1.020 do Ministério da Saúde (BRASIL, 2009)

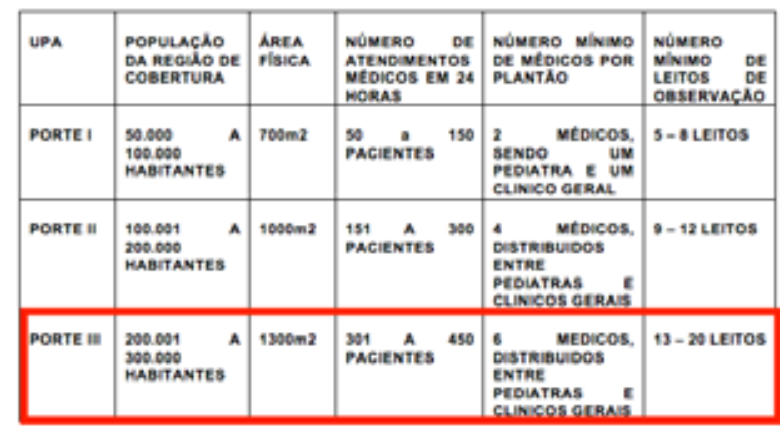

Fonte: Diário Oficial da União de 15/05/2009

Para o projeto de implantação da UPA de Samambaia e das demais UPAs do Distrito Federal, incluindo 
a UPA do Núcleo Bandeirante, Recanto das Emas e São Sebastião, o Governo do Distrito Federal baseou-se em um projeto arquitetônico padrão.

Segundo Karmam (2001), todo o projeto deve ser fruto do planejamento da equipe que está projetando o empreendimento, determinando, desta forma, quais atividades o estabelecimento pretende executar, assim como seu projeto. Projetos padrão são totalmente desaconselhados, pois para cada caso, há um projeto diferente: clientela, perfil epidemiológico, topografia, condições climáticas e outros fatores específicos para cada região que devem ser trabalhados unicamente em cada projeto. Tais fatores não foram considerados na implantação das UPAs do Distrito Federal.

O sistema construtivo adotado pela UPA de Samambaia é compatível com o sistema modular denominado de steel framing, produzido industrialmente. Os perfis metálicos são fabricados em chapa galvanizada com vedações em painéis revestidos internamente com material isopor. $\mathrm{O}$ edifício é apoiado em uma plataforma construída com perfis em chapas dobradas, sendo todo o piso flutuante construído em chapas de compensado revestidas internamente em manta vinílica.

A seguir serão analisados e avaliados os parâmetros da UPA de Samambaia, de acordo com as definições de conforto ambiental adotados neste estudo.

\subsection{Conforto Higrotérmico - UPA de Samambaia}

O clima no Distrito Federal é caracterizado como clima tropical de altitude, com épocas do ano bem definidas, sendo a estação de verão úmida, chuvosa e de inverno seca e fria.

A edificação possui um desempenho insatisfatório nos parâmetros de conforto higrotérmico. Como pode ser observado na Figura 2, os ventos predominantes se deslocam no sentido lesteoeste; a falta de aberturas na fachada, onde há predominância dos ventos, impede a entrada e troca de ar na edificação. A orientação solar da edificação foi implantada com aberturas principais no sentido sudeste-noroeste.

A UPA de Samambaia está localizada em um terreno com topografia de declividade baixa, implantada em uma área onde não há presença de vegetação e áreas aquíferas que possam melhorar a umidade da edificação. Ao analisar a área, observa-se que a entrada principal da Unidade está localizada à sudoeste, recebendo ventos secos e quentes; o vento seco do sul permeia a edificação trazendo poeira e poluentes, prejudicando a qualidade do ar da Unidade.

Figura 2: Mapa de locação - UPA de Samambaia

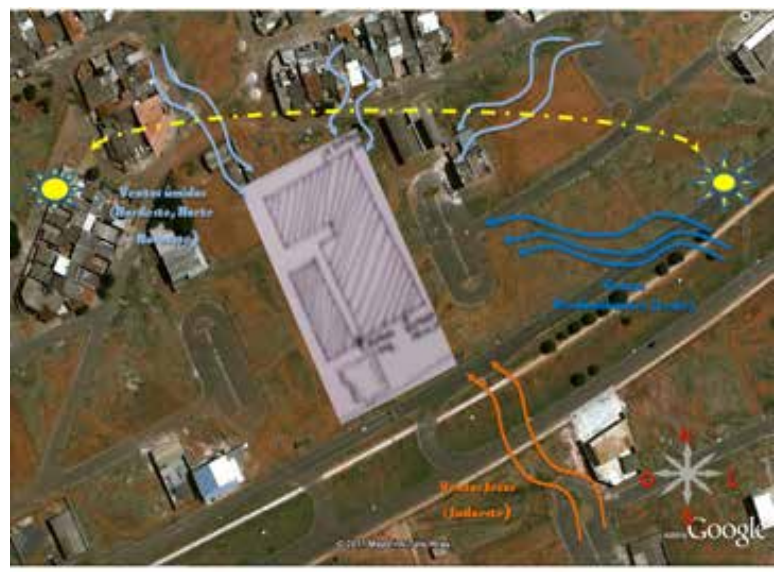

Fonte: Google Earth (2013)

Em relação à ventilação no interior da UPA, observou-se que ambientes como consultórios, sala de observação, recepção e demais áreas da Unidade não possuem circulação de ar devido à falta de aberturas de janelas na maioria dos ambientes, vide Figura 3. A ausência de aberturas pode ser prejudicial à saúde, uma vez que o ar não pode circular livremente, ficando viciado e podendo proporcionar a contaminação por aerossóis. Os únicos ambientes que possuem pequenas aberturas na UPA de Samambaia são os banheiros e os vestiários, conforme consta na Figura 4.

O sistema de condicionamento de ar na unidade é constituído por condicionadores de ar individuais, do tipo janela, não atendendo as normas RE $n^{\circ}$ 09 da ANVISA (BRASIL, 2003b), que estabelece padrões de qualidade do ar interior em ambientes climatizados artificialmente de uso público e coletivo e a norma ABNT NBR 7256 da ABNT Tratamento de ar em Estabelecimento Assistencial à Saúde (ABNT, 2005). Segundos funcionários do estabelecimento o sistema de ar é vinculado ao sistema de iluminação artificial que funciona vinte e quatro horas por dia.

Segundo a norma RE $n^{\circ} 09$ da ANVISA (BRASIL, 2003b), a Avaliação da Qualidade do Ar (QAI) é obrigatória para edificações cujo sistema de climatização tenha capacidade igual ou superior

1 Google Earth. Disponível em: <<https://www.google.com/earth/»>, $<<$ Acessado aos 20 de Abril de 2013>> 
a 5,0 TRs, resolução esta que não está sendo respeitada na unidade.

Figura 3: Recorte fotográfico da Sala de Recepção UPA de Samambaia

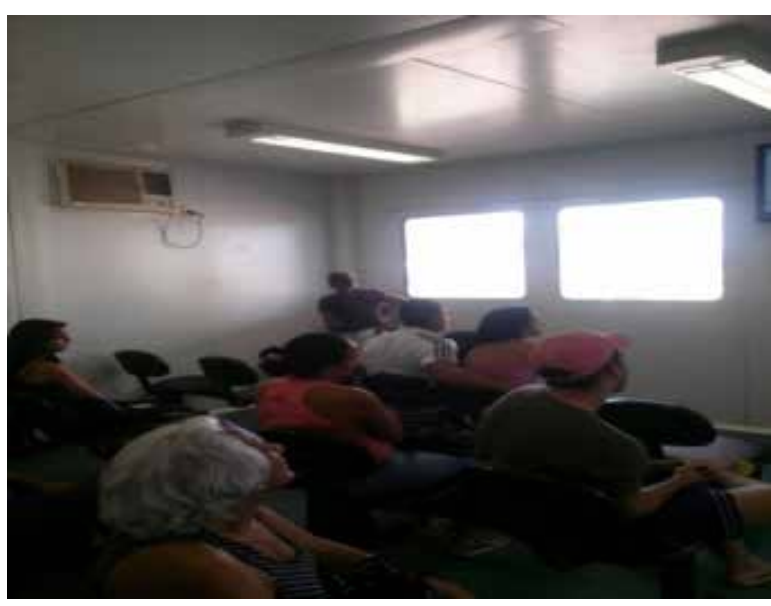

Fonte: O Autor (2013)

Figura 4: Recorte fotográfico da vista externa da Fachada Principal - UPA de Samambaia

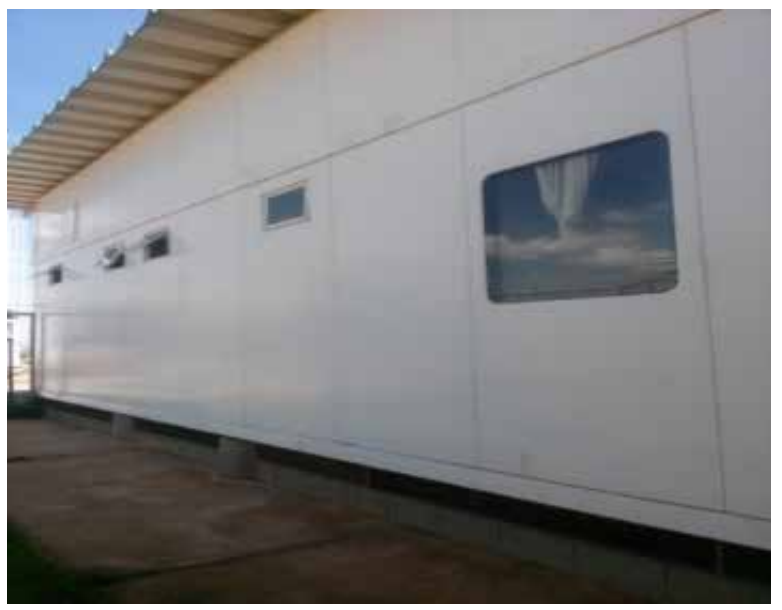

Fonte: O Autor (2013)

\subsection{Conforto Acústico - UPA de Samambaia}

A procura por tratamento médico, a internação e o trabalho por parte dos profissionais de saúde, são fatores que geram estímulos desagradáveis como o excesso de ruídos no ambiente ocasionados por fatores externos como equipamentos e vozes, por elementos de reverberação (piso, parede e teto, entre outros), e por elementos receptores (pessoas que ocupam o espaço). Além do desconforto auditivo encontrado na unidade, os ruídos podem provocar alterações fisiológicas e psicológicas nos pacientes que frequentam o ambiente, bem como na equipe de profissionais.

Observou-se também que um dos agravantes encontrados no ambiente é a forma de implantação e o material usado no piso. Devido à trepidação das macas, cadeiras de rodas e o intenso fluxo de pessoas, o piso da unidade apresenta ruídos e sensações de afundamento produzido pela circulação, vide Figura 5.

Figura 5: Recorte fotográfico da Sala de Espera - UPA de Samambaia

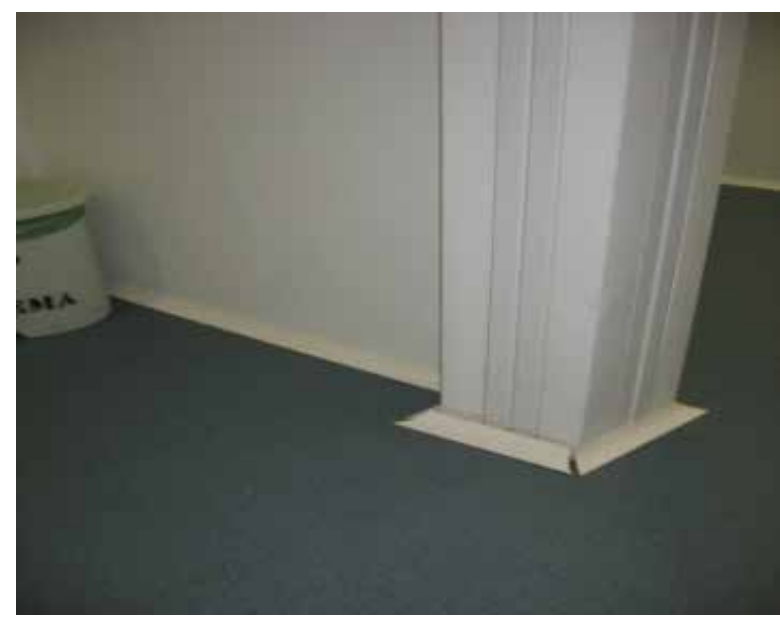

Fonte: O Autor (2013)

A fundação da UPA de Samambaia não apresenta condições adequadas, Figura 6, podendo comprometer a sustentação da obra a longo prazo, além de afetar outras características importantes na definição do conforto ambiental.

De acordo com Goés (2011), o ideal ao se projetar um EAS, incluindo unidades de urgência e emergência, é procurar encontrar soluções no uso de materiais acústicos, preferencialmente, que absorvam os sons, levando-se em consideração os aspectos da manutenção do controle das infecções hospitalares, da manutenção e movimentação dos equipamentos como pisos em mantas acústicas e anti-impactantes, forros de gesso acantonado, paredes protegidas de sons construídas de materiais com alta capacidade de absorção acústica. 
Figura 6: Recorte fotográfico da Fundação - UPA de Samambaia

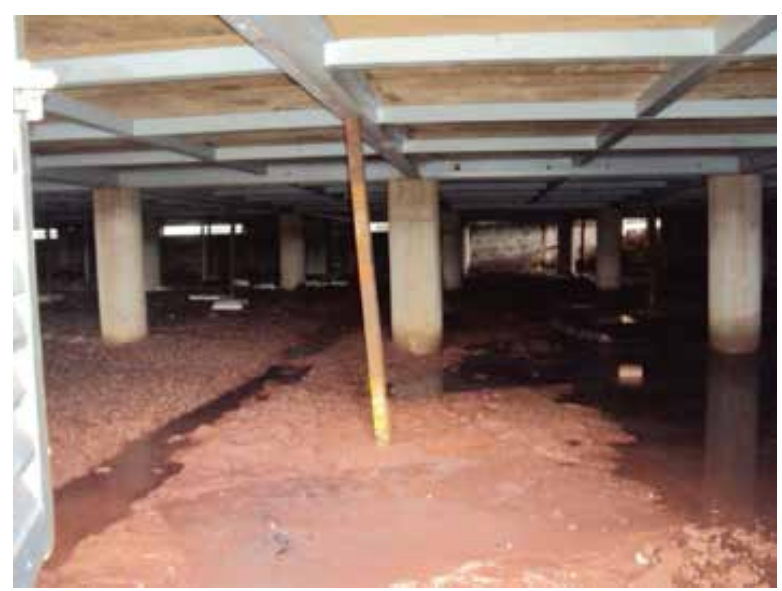

Fonte: O Autor (2013)

\subsection{Conforto Luminoso - UPA de Samambaia}

As condições de iluminação na unidade possui desempenho insatisfatório para o conforto ambiental dos ambientes internos. A iluminação existente na unidade é feita artificialmente por luminárias com lâmpadas que ficam acesas durante todo o dia. Há falta de iluminação natural em alguns ambientes da Unidade, fazendo com que os que pacientes e profissionais de saúde e demais funcionários percam a noção de tempo na UPA, alterando o relógio biológico humano.

A falta de iluminação natural é agravada devido à inexistência de janelas nas salas internas do estabelecimento, conforme pode ser observado nas Figura 7 e 8.

Figura 7: Recorte fotográfico da Sala de Recuperação - UPA de Samambaia

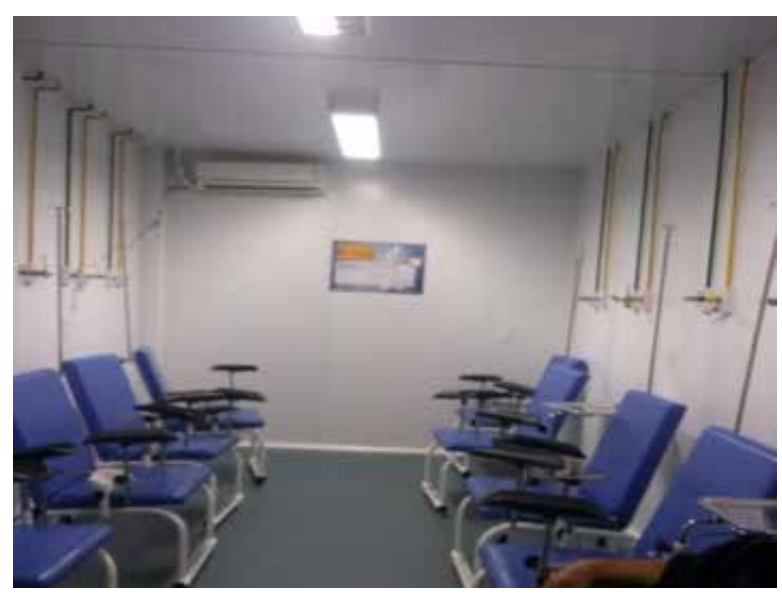

Fonte: O Autor (2013)
Figura 8: Recorte fotográfico da Sala Amarela - UPA de Samambaia

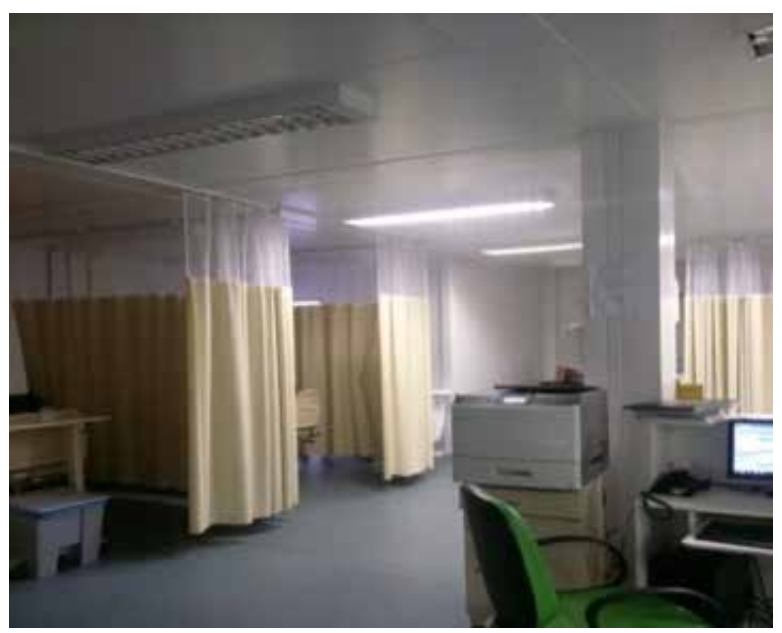

Fonte: O Autor (2013)

\subsection{Conforto Visual - UPA de Samambaia}

O conforto visual na UPA de Samambaia também é insatisfatório, tendo como cor predominante o branco. A cor branca traz um excesso de claridade para o local, fazendo com que o ambiente gere um cansaço mental para pacientes e servidores. A Unidade, além de possuir todos os ambientes internos pintados de branco, não possui a presença de iluminação natural, tornando assim o branco ofuscante devido a grande quantidade de iluminação artificial - Figura 9.

Figura 9: Recorte fotográfico da circulação interna UPA de Samambaia

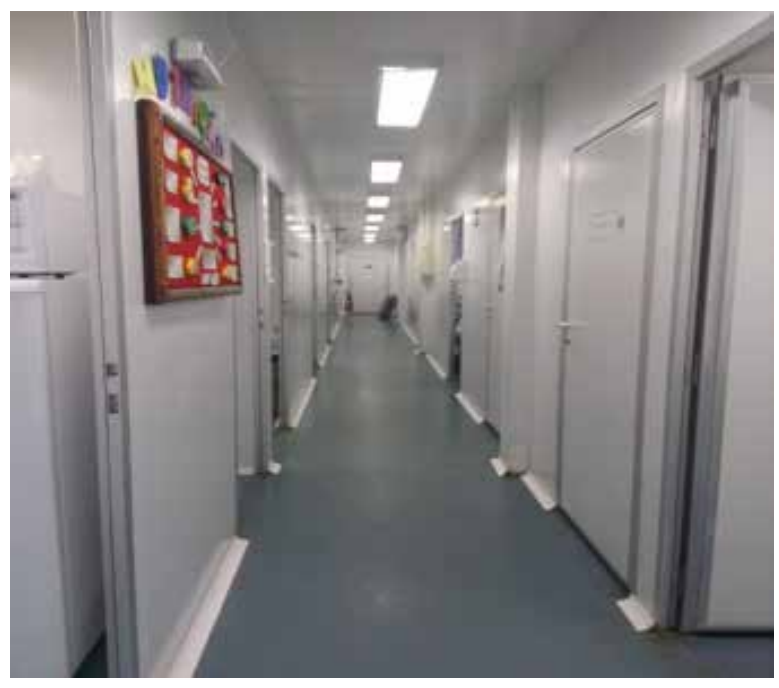

Fonte: O Autor (2013) 


\section{Discussão dos Resultados}

Com a finalidade de obter a impressão e percepção dos envolvidos e afetados pela operação da UPA de Samambaia, aplicou-se instrumentos de coleta de dados por meio de entrevistas individuais. $\mathrm{O}$ roteiro da entrevista foi estruturado e validado com questões objetivas relacionadas aos parâmetros de conforto ambiental, por meio de uma escala que varia entre ótima, bom, regular e ruim.

As atividades de campo aconteceram no mês de abril de 2014, totalizando vinte entrevistados. Destes, onze são servidores da UPA de Samambaia, um desempenha o papel de gestor, e os demais são usuários e pacientes dessa Unidade. Os entrevistados, usuários e pacientes da UPA de Samambaia, manifestavam recorrentemente insatisfação com o atendimento devido à falta de profissionais da saúde que pudessem atendê-los adequadamente, além das condições infraestruturais da Unidade, não obstante os pesquisadores esclarecerem os objetivos da pesquisa.

De um modo geral, e corroborando com as observações diretas realizadas quanto aos parâmetros de conforto ambiental, conforme descrito na Seção 5 deste artigo, as impressões dos entrevistados comprovam o grau de insatisfação a respeito da avaliação de conforto ambiental na Unidade.

No geral, os servidores apontaram que os ambientes internos à Unidade possuem a renovação de ar prejudicada pela falta de manutenção dos aparelhos condicionadores de ar.

As salas denominadas de Sala Amarela e Vermelha, que correspondem aos ambientes de internação, sofrem com a falta de ventilação e iluminação natural e de renovação do ar. Os servidores relatam que em alguns momentos do dia o cheiro e o ar viciado dos ambientes exalam por toda parte, prejudicando a permanência das pessoas naquele estabelecimento.

No quesito conforto acústico, enfatizou-se a falta de privacidade que os fechamentos das paredes proporcionam e pelo som emitido pelo piso. Segundo pacientes e servidores, ao caminhar pelas dependências da Unidade a sensação de afundamento é notada. Além desses relatos, os servidores ainda lembraram que evitam usar salto alto devido à grande trepidação do piso da UPA de Samambaia.

\section{Conclusão}

Observa-se que a arquitetura hospitalar possui diversas alternativas, em termos de conceitos de conforto ambiental, para tornar o ambiente agradável e confortável, a partir dos estudos realizados no decorrer desta investigação.

O conforto ambiental é um forte aliado na arquitetura hospitalar, ao mesmo tempo em que colabora com o processo terapêutico do paciente, contribui também para a qualidade dos serviços de saúde prestados pelos profissionais envolvidos.

Durante o desenvolvimento da pesquisa, constatouse que a UPA de Samambaia não atende os requisitos de conforto ambiental preconizadas na literatura, normas e resoluções vigentes.

O objetivo geral do trabalho foi mostrar essas discrepâncias do conforto ambiental implantadas na Unidade de Samambaia, e mostrar por meio da literatura que as soluções encontradas para futuras instalações de unidades de pronto atendimento devem ser aparelhadas de modo a favorecer a implementação dos requisitos de conforto ambiental.

Este estudo não tem a pretensão de generalizar os resultados e a análise alcançados, uma vez que o objeto investigado apresenta suas idiossincrasias e particularidades no tocante a questões políticas, demográficas e psicossociais.

Como sugestão de estudos futuros, os pesquisadores acreditam que uma investigação abrangente, cobrindo Estados e Regiões do Brasil podem demonstrar o quanto essas UPAs estão preparadas para contemplar os parâmetros de conforto ambiental.

\section{Referências}

ABNT. Norma ABNT - NBR 7256. Tratamento de Ar em Estabelecimento Assistencial à Saúde. 2005.

BRAGA, Darja Kos; AMORIM, Cláudia, N. D. Métodos e Técnicas para Conforto Ambiental e Reabilitação do Espaço Construído. Apostila do Curso de Pós-Graduação em Reabilitação Ambiental Sustentável Arquitetônica e Urbanística - Reabilita 5. FAU-UNB. Brasília. 2013. 
BRASIL. Portaria $N^{\circ} 1.020$, de 13 de Maio de 2009. Estabelece diretrizes para a implantação do componente pré-hospitalar fixo para a organização de redes locorregionais de atenção integral às urgências em conformidade com a Política Nacional de Atenção às Urgências, 2009.

BRASIL. Ministério da Saúde. Secretaria-Executiva. HumanizaSUS: Política Nacional de Humanização. Brasília: Ministério da Saúde, 2003.

BRASIL. Agência Nacional de Vigilância Sanitária. Resolução RE $n^{\circ}$ 09, de 16 de Janeiro de 2003. Dispõe sobre orientação técnica elaborada por grupo técnico assessor sobre padrões referenciais de qualidade do ar interior em ambientes climatizados artificialmente de uso público e coletivo. Brasília, 2003.

BRASIL. Portaria GM/MS 2.048, de 05 de Novembro de 2002. que implanta as Unidades de Pronto Atendimento em todo território nacional, 2009.

BRASIL. Agência Nacional de Vigilância Sanitária. Resolução RDC/ANVISA ${ }^{\circ}$ 50, de 21 de Fevereiro de 2002. Dispõe sobre o regulamento técnico para planejamento, programação, elaboração e avaliação de projetos físicos de Estabelecimentos Assistenciais de saúde. Brasília, 2002.

CORBELLA, Oscar; YANNAS, Simos. Em busca de uma arquitetura sustentável para os trópicos. Ed. Revan, Rio de Janeiro, 2003.

GEMELLI, C. B. Avaliação de Conforto Térmico, Acústico e Lumínico de Edificação Escolar com Estratégias Sustentáveis e Bioclimáticas: o caso da Escola Municipal de Ensino Fundamental Frei Pacífico. Dissertação de Mestrado em Engenharia Civil. Programa de Pós-Graduação em Engenharia Civil, UFRGS, Porto Alegre, 2009.

GOÉS, Ronald. Manual Prático de Arquitetura Hospitalar. São Paulo: Blucher, 2ª edição, 2011.

. Manual Prático de arquitetura Hospitalar. São Paulo: Blucher, $1^{a}$ edição, 2004.

KARMAM, Jarbas. Manutenção Hospitalar Prediativa. São Paulo: PINI, 2001

MEDEIROS, Luciana de. Humanização Hospitalar, ambiente físico e relações assistenciais: a percepção de arquitetos especialistas. Dissertação de Mestrado em Psicologia. Centro de Ciências Humanas, Letras e Artes. Universidade Federal do Rio Grande do Norte, Natal, 2004.

OLIVEIRA, T. A.; RIBAS, O T. Série Saúde \& Tecnologia - Textos de Apoio à Programação Física dos Estabelecimentos Assistenciais de Saúde Sistemas de Controle das Condições, 2009. 

Eixo 02

\section{A inserção de áreas verdes, arborização ou agricultura urbana como melhora da qualidade dos espaços livres}

43 Reabilitação ambiental: a vegetação além do paisagismo

CORRÊA; Rodrigo Studart

51 Reabilitação ambiental no igarapé da Fortaleza - O Parque do igarapé e seu paisagismo ecológico

DOS SANTOS; Géssica Nogueira; MEDEIROS, José Marcelo Martins

61 Desafios do planejamento urbano no Brasil e seus marcos legais sob a ótica da agricultura urbana

LEMOS, Natália da Silva; ANDRADE, Liza Maria de Souza; MEDEIROS, Valério Augusto Soares de 
